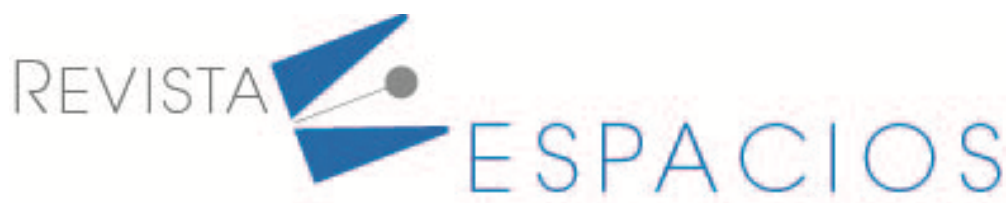

\title{
Desconstruindo a narrativa da SECOM em seu post do Dia do Agricultor: o crescimento da insegurança alimentar no Brasil frente aos ganhos do agronegócio durante a pandemia da Covid-19
}

\section{Deconstructing the SECOM narrative in its post on the Farmer's Day: the growth of the food insecurity in Brazil face the gains of the agribusiness during Covid-19 pandemic}

\begin{abstract}
ARACRI, Luís A. ${ }^{1}$
\section{Resumen}

Baseado em uma live transmitida para os estudantes de graduação matriculados na disciplina Geografia Agrária, oferecida no primeiro semestre do ano letivo de 2021 pelo Departamento de Geociências da Universidade Federal de Juiz de Fora, o presente artigo tem por objetivo propor uma reinterpretação crítica e com base em dados oficiais da mensagem publicada pela Secretaria Especial de Comunicação Social da Presidência da República (SECOM) do Governo Brasileiro celebrando o Dia do Agricultor, na qual enfatizava a capacidade dos agricultores brasileiros de "garantir comida na mesa de milhões de pessoas no Brasil e no mundo", ao mesmo tempo em que omitia o aumento da insegurança alimentar no país durante a pandemia da Covid-19 e o crescimento dos lucros do agronegócio mesmo diante desse cenário.
\end{abstract}

Palabras clave: insegurança alimentar, agronegócio, redes sociais, SECOM

\begin{abstract}
Based on a live broadcast for undergraduate students registered in the Agrarian Geography course, offered in the first semester of the 2021 academic year by the Department of Geosciences of the Federal University of Juiz de Fora, this paper aims to propose a critical reinterpretation (based in official data) of a post published by the Secretaria Especial de Comunicação Social da Presidência da República (SECOM) of the Brazilian Government celebrating the Farmer's Day, in which it was emphasized the ability of Brazilian farmers to "guarantee food on the table of millions of people in Brazil and abroad", while omitting the increase in food insecurity in the country during the Covid-19 pandemic and the growth of agribusiness profits even in this scenario.

Key words: food insecurity, agribusiness, social networks, SECOM
\end{abstract}

\footnotetext{
${ }^{1}$ Doutor em Geografia pela Universidade Federal do Rio de Janeiro. Professor Associado do Instituto de Ciências Humanas da Universidade Federal de Juiz de Fora. E-mak: luis.aracri@ufjf.edu.br
} 


\section{Introdução}

O presente artigo se baseia em uma live transmitida através do ambiente virtual de aprendizagem Google Classroom no dia 16 de agosto de 2021 e que tinha como público-alvo estudantes matriculados na disciplina Geografia Agrária, que foi oferecida no primeiro semestre letivo do referido ano pelo Departamento de Geociências da Universidade Federal de Juiz de Fora para os cursos de graduação em Geografia (nas modalidades bacharelado e licenciatura), Turismo e do Bacharelado Interdisciplinar em Ciências Humanas. $O$ título da live era "O crescimento da insegurança alimentar e a alta dos ganhos do agronegócio no Brasil durante a pandemia da Covid-19: os dois lados da mesma moeda" e foi motivada por uma postagem, realizada no dia 28 de julho de 2021, pela Secretaria Especial de Comunicação Social da Presidência da República (SECOM) em seus perfis institucionais nas redes sociais (Twitter e Instagram), que provocou reações indignadas em parte da opinião pública, em grande parte por exibir a imagem de um homem armado com uma espingarda, o que, por sua vez, reforçava a posição favorável do governo do presidente Jair Bolsonaro com relação à ampliação da posse de armas pela sociedade, o que inclui a população rural.

O objetivo do referido post era celebrar o Dia do Agricultor. O Decreto de Lei n. 48.630, de 1960, instituiu o dia 28 de julho como sendo o Dia do Agricultor porque nessa data e no ano em que o decreto foi publicado comemorou-se os 100 anos de criação, por Dom Pedro II, da Secretaria de Estado dos Negócios da Agricultura, Comércio e Obras Públicas, um órgão que, no seu tempo, seria o equivalente a um Ministério da Agricultura. A controvérsia envolvendo a imagem escolhida pela SECOM para ilustrar o post gerou um grande debate nas redes sociais e na mídia, de modo que a pressão da opinião pública forçou o órgão a retirar a publicação do ar, tanto do Instagram quanto do Twitter. Inclusive, vale dizer que a foto, na verdade, era de um caçador e foi obtida em um banco de imagens. Essa imagem, por si só, renderia um debate pertinente sobre o aumento da violência no campo no Brasil, tendo em vista que os conflitos nas áreas rurais são objeto de interesse da Geografia Agrária. Entretanto, o post da SECOM continha outros elementos dignos de reflexão, mas que, infelizmente, receberam uma atenção proporcionalmente menor ${ }^{1}$.

O post da SECOM em questão não se limitava a uma imagem; ele continha, também, textos. E estes, por sua vez, podem ser considerados parte de uma construção narrativa que, nesse caso, propunha uma determinada representação ou idealização sobre o campo e o "agro" no Brasil. A questão é: em que medida essa narrativa corresponde à realidade empírica? Acreditamos que a única maneira de responder a essa pergunta é com base em dados, isto é, com base na ciência. Na publicação feita no Instagram, sobre a imagem do homem armado havia um pequeno texto onde se lia "28 de Julho. Dia do Agricultor. Alimentando o Brasil e o Mundo". No Twitter, por sua vez, a mesma imagem vinha acompanhada da seguinte legenda: "Hoje homenageamos os agricultores brasileiros, trabalhadores que não pararam durante a crise da Covid-19 e garantiram comida na mesa de milhões de pessoas no Brasil e ao redor do mundo". Essas três linhas elaboradas pela SECOM resumem de maneira completa a narrativa do Governo Federal, portanto oficial, sobre o setor agropecuário brasileiro. É uma narrativa que se traduz no discurso do Brasil como potência agrícola, do país com "vocação histórica" para agropecuária, do território com grande disponibilidade de terras férteis, da nação que tem no campo e na agricultura suas maiores fontes de riqueza (Daré, 2007). Não se trata exatamente de um discurso novo. Entretanto, essa narrativa acomodou um novo elemento, que desta vez tem origem no contexto atual: o discurso de que o campo não

\footnotetext{
${ }^{1}$ Tendo em vista que as postagens da SECOM foram removidas tanto do Twitter quanto do Instagram, não foi possível reproduzir no presente artigo a polêmica imagem em questão.
} 
parou durante a crise da Covid-19, e que não o fez porque não podia se permitir tal "luxo", porque senão o país afundaria econonomicamente, ou então o povo sofreria com a fome.

Entretanto, até que ponto os dados de que dispomos - sendo que a grande maioria deles foram produzidos por órgãos do próprio Governo Federal - corroboram essa narrativa? Ou em que medida a contradizem? O que se viu na verdade, e estamos falando de algo amplamente documentado e noticiado pelos grandes meios de comunicação do país, é que a insegurança alimentar e a fome vêm aumentando no Brasil desde o início da chamada "crise da Covid-19", o que contraria a afirmação da SECOM em suas postagens do último Dia do Agricultor. Por outro lado, apesar dessa preocupante situação, o agronegócio brasileiro, no mesmo período, viu seus ganhos aumentarem. A hipótese que aqui defendemos é que esses dois fenômenos possuem relação entre si; eles são, como o dissemos na mencionada live, os "dois lados de uma mesma moeda". O que estamos a propor aqui é a desconstrução, fundamentada em dados oficiais, do discurso da SECOM segundo o qual a comida na mesa de milhões de pessoas no Brasil (principalmente) e no resto do mundo tem sido garantida. Procuraremos demonstrar, dessa forma, que o setor agropecuário brasileiro, em particular o setor de agronegócios, vem conseguindo incrementar seus ganhos apesar das dificuldades crescentes de parte da população de ter acesso a comida.

\section{Metodologia}

De acordo com Januzzi (2006), os indicadores sociais, como aqueles que descrevem, por exemplo, situações como as de segurança/insegurança alimentar, ou os que apontam os superávits do agronegócio, são construídos a partir de estatísticas econômicas, sociais ou demográficas públicas cujos dados são levantados através de diversas pesquisas ou, então, fazem parte de registros administrativos. A disponibilidade dessas estatísticas e desses indicadores, compilados e disseminados por diversas agências, possibilita o diagnóstico da realidade social empírica do país e, portanto, pode servir à análise e desconstrução críticas de discursos e narrativas sobre diferentes aspectos que tentam falsear ou distorcer essa mesma realidade.

Com vistas ao alcance do objetivo proposto na Introdução do presente artigo, trabalhamos com os dados fornecidos pelos levantamentos a seguir: Pesquisa Nacional por Amostra Domiciliar (PNAD) e Índice de Preços ao Consumidor Amplo (IPCA), ambos de responsabilidade do Instituto Brasileiro de Geografia e Estatística (IBGE); as Notas de Conjuntura do Comércio Exterior do Agronegócio Brasileiro, produzidas pelo Instituto de Pesquisa Econômica Aplicada (IPEA); Gestão dos Estoques Públicos da Companhia Nacional de Abastecimento (CONAB). O recorte temporal principal é o dos primeiros doze meses da pandemia da Covid-19 no Brasil (de março de 2020 a março de 2021), mas, quando se fez necessário, recorremos a dados de períodos anteriores para fins de contextualização. Além disso, acessamos, também, estatísticas privadas, a exemplo do Índice Nacional de Vendas da Associação Brasileira de Supermercados (ABRAS) e o ranking das maiores empresas processadoras de carne do mundo produzido pela National Provisioner.

Os dados obtidos a partir dessas estatísticas foram submetidos a analises qualitativas com base nos trabalhos de pesquisadores que vêm se dedicando à análise do "agro" brasileiro sob diferentes aspectos, como Aracri (2012), Bernardes (1996 e 2010), Elias (2021), Mazzali (1999) e Wesz Jr. (2011), principalmente. Além disso, o presente trabalho recorreu, em caráter eventual, à pesquisa documental, obtendo dados e informações complementares através de portais de notícias na internet ou de sites de empresas ligadas ao setor de agronegócios.

\section{Resultados e discussão}

Nosso ponto de partida é a afirmação contida no post da SECOM sgundo a qual a agricultura brasileira "garante comida na mesa de milhões de pessoas no Brasil e no mundo". É preciso começar a análise "olhando para 
dentro", isto é, para o próprio território nacional. E tomaremos como recorte temporal principal o período da "crise da Covid-19", que teve início no país em março de 2020. A Rede Brasileira de Pesquisa em Soberania e Segurança Alimentar e Nutricional, conhecida como "Rede PENSSAN", divulgou, através da FAO (Food and Agriculture Foundation, da ONU) o "Inquérito Nacional Sobre Insegurança Alimentar no Contexto da Pandemia da Covid-19 no Brasil". Esse inquérito, que é uma espécie de relatório, foi feito com base nos dados da PNAD, (pesquisa produzida pelo IBGE, órgão ligado ao Ministério da Economia). O relatório apontou o seguinte: em 12 meses de pandemia, isto é, de março de 2020 a março de 2021, 55,2\% dos domicílios brasileiros, ou seja, mais da metade, entraram em situação de "insegurança alimentar".

A insegurança alimentar é quando um segmento da população de uma região ou país encontra restrições e limitações ao acesso a alimentos nutritivos ou que atendam às necessidades dietéticas para uma vida saudável. $O$ inquérito da Rede PENSSAN mostra ainda que durante o mesmo período $9 \%$ dos domicílios brasileiros entraram em situação de "insegurança alimentar grave", que é sinônimo de fome. Desse total de domicílios em situação de insegurança alimentar grave, $12 \%$ estão no campo. O que esses dados nos mostram, de imediato, é que não apenas a comida na mesa de milhões no Brasil não está garantida, como uma parte significativa dessas mesas sem comida está no próprio campo.

Por trás desse cenário, temos uma combinação trágica entre a alta no preço dos alimentos e queda nos níveis de renda da população. Segundo o IPCA, que também é calculado pelo IBGE, nos mesmos doze meses do levantamento realizado pela Rede PENSSAN, a alta acumulada do preço dos alimentos foi de $15 \%$, o que é quase o triplo acima da inflação no mesmo período (que foi de 5,20\%). Os produtos que foram responsáveis por essa alta foram, principalmente, o óleo de soja (82\%), o arroz (57\%), o feijão (42\%) e as carnes (35\%). Por outro lado, do total de domicílios sem nenhuma renda do trabalho, passamos, também segundo a PNAD, de $25 \%$ no primeiro trimestre do ano passado, para $29,3 \%$ no primeiro trimestre de 2021 . No primeiro trimestre deste ano, ainda segundo o IBGE, o desemprego subiu 14,7\%; no primeiro trimestre do ano passado, ou seja, no período prépandemia, o desemprego já havia registrado alta de $12,2 \%$, o que significa um crescimento mais ou menos no mesmo patamar do primeiro trimestre de 2019 , que foi $12,7 \%$. Isso quer dizer que o crescimento do desemprego no país precede a pandemia. Foram pelo menos três anos seguidos nos quais o primeiro trimestre registrou aumento no número de pessoas desempregadas.

Por trás da alta no preço dos alimentos, existem diversos fatores. Por ora, cabe destacar dois: (1) a alta no preço dos combustíveis, o que encarece despesas com frete (há, portanto, um repasse do aumento desse custo para o consumidor final); (2) alta do dólar, pois muitos dos componentes utilizados nos insumos agrícolas, como é o caso de compostos químicos empregados na fabricação de defensivos e fertilizantes, são importados (Aracri, 2012). Existe um terceiro fator importante a ser considerado, mas o abordaremos um pouco mais adiante.

O fato é que, apesar desse cenário, que contradiz, pelo menos em parte, a afirmação da SECOM de que a comida está garantida na mesa de milhões de brasileiros, temos, no outro extremo, um segundo cenário que também chama muito a atenção. O IPEA (que também está vinculado ao Ministério da Economia) publicou, no dia 12 de agosto de 2021, o fechamento dos dados do mês anterior do comércio exterior do agronegócio brasileiro. De acordo com o instituto, o agronegócio brasileiro fechou o mês de julho com superávit de US\$10,1 bilhões, ou aproximadamente R\$ 53 bilhões (segundo câmbio do dia 16 de agosto de 2021). Temos aí, então, um violento contraste: de um lado, o aumento da insegurança alimentar e da fome, incluindo a fome no campo, propiciado pela mencionada "combinação trágica" entre desemprego, diminuição da renda e alta no preço dos alimentos; de outro, o agronegócio brasileiro registrando ganhos crescentes. O que parece uma contradição é, na verdade, "os dois lados de uma mesma moeda", ou seja, são as duas faces de um mesmo fenômeno (Elias, 2021). Mas como explicar, então, essa relação? 
O ponto de partida para entender isso é identificar quais produtos impulsionaram esse superávit do agronegócio brasileiro e, na sequência, traçar o destino desses produtos. Segundo o IPEA, são produtos que integram o comércio exterior brasileiro participando das exportações do país. Segundo os dados do mês de julho de 2021, que foram fechados em agosto, esses produtos foram a soja, o milho, o açúcar e a carne bovina, ou seja, são produtos que tiveram, de acordo com o IPEA, uma variação positiva do preço médio no mercado externo. É aí que entra o outro fator importantíssimo para entender a alta no preço dos alimentos no Brasil, um dos pilares do aumento da insegurança alimentar durante a pandemia da Covid-19. Se por um lado a desvalorização do real frente ao dólar impacta de modo negativo os custos de produção, por outro torna as exportações de produtos agropecuários, ou seja, a venda para o mercado externo, em vez do mercado interno, mais atraente.

Isso quer dizer que o dólar caro faz com que os produtores rurais priorizem as exportações, o que provoca um "esvaziamento" do mercado doméstico, fazendo diminuir a oferta e, consequentemente, contribuindo para a elevação dos preços no mercado interno. No câmbio monetário, os empresários rurais acabam ganhando, porque exportam em dólar, mas ganham cinco vezes ou mais em reais. Essa não é uma estratégia necessariamente nova, quer dizer, trata-se de uma prática comum que antecede a pandemia. De acordo com a CONAB, em dez anos os estoques públicos de alimentos caíram $96 \%$ em relação à média anual, sendo que não existem estoques públicos de soja desde 2013. A principal função dos estoques públicos é a de justamente manter controle sobre o preço dos alimentos no mercado interno.

O que aconteceu durante a pandemia foi o seguinte: com a brutal desvalorização do real, para os países que importam, isto é, para as economias estrangeiras que compram nossos produtos agropecuários, é como se estes estivessem "em liquidação". Logo, aumentou a procura externa por produtos brasileiros, o que, consequentemente, afetou os estoques internos. Com a maior parte da soja sendo destinada ao mercado externo, temos alta no preço do óleo de soja nas gôndolas de supermercado; com as carnes bovinas "puxando" as exportações do agronegócio brasileiro, o preço delas no mercado interno subiu acima de 30\%; já o açúcar segundo o IPEA, teve variação positiva no seu preço no mercado externo de $14,7 \%$, o que significa que as usinas estão priorizando a transformação da cana em açúcar refinado para exportação, o que explica a alta acumulada de $65,2 \%$ no preço do etanol de maio de 2020 a maio de 2021, segundo o IPCA.

Dito de maneira muito resumida e direta, o que os dados mostram é que o agronegócio não prioriza a mesa dos trabalhadores brasileiros. Isso porque, historicamente, os alimentos que compõem a cesta básica da população brasileira vêm, em grande parte, da agricultura familiar, não do agronegócio (Elias, 2021). Entretanto, cabe agora responder outra questão: qual então o verdadeiro destino da produção do agronegócio brasileiro? Seja no país ou no exterior, os produtos do setor de agronegócios se destinam: (a) à indústria de de alimentos semiprocessados, processados e ultraprocessados, além de grandes cadeias de fast food (Wesz Jr., 2011; Mazzali, 1999); (b) à indústria de bioenergia (Houtard, 2010; Trentini e Macchione Saes, 2010); (c) à indústria de produtos para nutrição animal, como rações para a criação de bovinos, suínos e aves em sistemas de semi-confinamento ou de confinamento pleno (Schuck, Luglio e Carvalho, 2018); (d) a outros setores industriais, como o de cosméticos, ou o de papel e celulose; (e) às grandes redes de supermercados (Elias, 2021).

Particularmente com relação às redes de supermercados, há um outro dado digno de nota: estas também lucraram bastante durante a pandemia, apesar da alta no preço dos alimentos e da queda nos níveis de renda da população. Tomemos como exemplo a rede Carrefour no Brasil: o jornal Valor Econômico publicou uma matéria em fevereiro de 2021 no qual dizia que os lucros líquidos da multinacional francesa no Brasil duplicaram ao longo do ano de 2020 e que suas vendas brutas, nesse período, tiveram um aumento de 20\% (Mattos e Brandão, 2021). Dois fatores contribuíram para isso. De um lado, alimentos mais caros. A princípio, a associação entre preços altos e queda nos níveis de renda deveria se refletir em baixa nas vendas, porém, do outro lado, parte da população residente nos domicílios que não se encontrava em situação de insegurança alimentar entre 
março de 2020 e março de 2021 passou a se alimentar mais em casa por causa do trabalho remoto - ou seja, essa parcela passou a ir mais ao supermercado para comprar comida durante a pandemia. Aí temos o outro aspecto trágico que foi omitido na postagem da SECOM: as grandes redes de supermercados tiveram aumento nos seus lucros durante à pandemia graças a menos da metade dos domícilios brasileiros. Segundo o Índice Nacional de Vendas calculado pela ABRAS, em maio deste ano o setor registrou crescimento de $12 \%$ em relação a maio do ano passado.

Há ainda outra pergunta a ser respondida: será que estamos mesmo colocando comida na mesa de milhões pelo mundo? Comecemos pelo caso da soja, que é o carro-chefe das exportações do agronegócio brasileiro, para responder a essa questão. A soja não é um alimento consumido in natura; na verdade ela é uma matéria-prima vegetal utilizada na produção de outros alimentos, para consumo humano, ou então para a nutrição de rebanhos. O maior comprador da soja brasileira é a China e ela é adquirida grande parte in natura para processamento em território chinês. As maiores agroindústrias processadoras chinesas são: a COFCO Group, que compra cerca de $25 \%$ do total da soja que o Brasil exporta para a China; o Jiusan Group, que durante o governo do presidente Donald Trump deixou de comprar soja dos EUA para comprar grãos brasileiros; e o Chongqing Grain Group, que tinha um projeto de construir a maior planta industrial de processamento de soja em Barreiras, na Bahia, mas o projeto está parado.

O subproduto mais nobre da soja é o farelo (Bernardes, 1996). Ele é utilizado na produção da torta a partir da qual são fabricadas rações para a criação de bovinos, aves e suínos. A produção de farelo permite a integração entre a cadeia produtiva da soja e a cadeia produtiva das proteínas animais, possibilitando a agregação de valor às carnes antes mesmo do seu processamento industrial (Mazzali, 1999; Bernardes, 2010). A criação de animais confinados, alimentados à base de rações, permite a produção em maior escala, em ciclos mais curtos e com adição de valor - e somente dessa forma é possível atender a demanda da indústria de carnes processadas, no Brasil e no exterior. Em outras palavras, o objetivo final não é colocar carne in natura na mesa da população. Mas carnes processadas, com alto valor agregado. A National Provisioner, que é um órgão de mídia e informação relacionado ao setor de carnes, realizou em 2018 um ranking das maiores empresas processadoras de carnes do mundo com base em um survey próprio. Das dez primeiras colocadas, nove tem origem nos Estados Unidos, dentre elas a Tyson Foods e a Cargill, que são as maiores. Em outras palavras: o agronegócio, que é quem exporta a maioria esmagadora dos produtos agropecuários brasileiros, vende para indústrias, não para pessoas.

\section{Conclusões}

Como pudemos observar, o aumento da insegurança alimentar no Brasil, apoiado pela alta no preço dos alimentos e pela queda no nível de renda da população, o superávit do agronegócio e os aumento dos lucros do setor supermercadista não são inconciliáveis. Pelo contrário, são fenômenos conectados. E quando examinamos a relação que existe entre eles, com base nos dados apresentados, percebemos que mesmo faltando comida na mesa de muitos trabalhadores neste país, um problema que se aprofundou durante a pandemia, há setores ligados à produção e comercialização de alimentos no Brasil que não deixaram de obter ganhos. Setores, portanto, indiferentes ao fato de que mais da metade dos domicílios brasileiros, hoje, encontra dificuldades de obter alimentos de qualidade ou que sequer conseguem acessar qualquer tipo de alimento.

Sendo assim, a postagem feita pela SECOM no último Dia do Agricultor é uma peça-chave do processo de construção de uma narrativa enviesada sobre o campo brasileiro. A ciência tem, por sua vez, o papel e o dever de produzir contra-narrativas. Daí a importância da pesquisa e da produção do conhecimento. Precisamos valorizar a ciência não apenas porque precisamos enfrentar uma grande crise sanitária como essa que estamos atravessando agora, mas também porque precisamos saber como o país está sendo impactado por essa crise sob diferentes aspectos: econômicos, sociais, políticos etc. 
É preciso saber em que medida alguns problemas crônicos do país foram agravados durante a pandemia ou até que ponto esse agravamento tem ou não relação com a crise da Covid-19. Precisamos saber também porque alguns setores da sociedade obtiveram elevados ganhos durante a pandemia, além de como conseguiram esses ganhos e por que, enquanto outros setores parecem ter sido ainda mais castigados. Acreditamos que, sem esse conhecimento, seremos facilmente induzidos a uma percepção distorcida dos fatos, principalmente através do que vem sendo veiculado nas redes sociais, tendo em vista que elas se incorporaram de maneira definitiva ao nosso cotidiano e se tornaram a principal fonte de informação para uma grande parcela da população.

\section{Referencias bibliográficas}

Aracri, L. A. (2012). Reestruturação produtiva, território e difusão de inovações no campo. 1ạ ed. Rio de Janeiro: Arquimedes.

Bernardes, J. A. (2010). O novo tempo do capital no Cerrado: a criação de novos territórios produtivos. En: Bernardes, J. A., e ARACRI, L. A. (eds.). Espaço e circuitos produtivos: a cadeia carne/grãos no Cerrado Matogrossense. 1aㅡ. ed. Rio de Janeiro: Arquimedes.

Bernardes, J. A. (1996). As estratégias do capital no complexo soja. En: Corrêa, R. L., Castro, I. E., y GOMES, P. C. (eds.). Brasil: questões atuais da reorganização do território. 1aㅡ ed. Rio de Janeiro: Bertrand Brasil (pp. 325-366).

Daré, R. (2007). O espaço agrário brasileiro nas reportagens da revista Veja das décadas de 1990 e 2000. Viçosa: Departamento de Artes e Humanidades da Universidade Federal de Viçosa. Recuperado de: http://www.geo.ufv.br/wp-content/uploads/2013/08/Raquel-Dare.pdf

Elias, D. (2021). O alimento-mercadoria e a fome no Brasil. Boletim Goiano de Geografia. Volume 41 (e69103), 1-35. Recuperado de: https://revistas.ufg.br/bgg/article/view/69103/36944 DOI: 10.5216/BGG.v41.69103

Houtard, F. (2010). A agroenergia: solução para o clima ou saída da crise do capital? 1a ed. Petrópolis: Vozes.

Januzzi, P. (2006). Indicadores sociais no Brasil: conceitos, fontes de dados e aplicações. 1ạ ed. Campinas: Alínea Edições.

Mattos, A., e Brandão, R. (2021). Lucro do Carrefour dobra em 2020. Valor Econômico. Edição de 12 de fevereiro de 2021. Recuperado de: https://valor.globo.com/empresas/noticia/2021/02/19/lucro-docarrefour-dobra-em-2020.ghtml

Mazzali, L. (1999). O processo recente de reorganização agroindustrial: do complexo à organização em rede. 1a ed. São Paulo: Editora Unesp.

Schuck, C., Luglio, A., e Carvalho G. Maior parte dos grãos vira ração, não alimento humano. Época Negócios. Abril de 2018. Recuperado de: https://epocanegocios.globo.com/colunas/noticia/2018/04/maior-partedos-graos-vira-racao-e-nao-alimento-humano.html

Trentini, F., e Macchione Saes, M. S. (2010). Sustentabilidade: o desafio dos biocombustíveis. 1ạ ed. São Paulo: Annablume.

Wesz Jr., V. (2011). Dinâmicas e estratégias das agroindústrias de soja no Brasil. 1a ed. Rio de Janeiro: e-Papers.

\section{$(\mathrm{cc})$ EY-NC}

Este trabalho está sob uma Licença Creative Commons

Atribuição-NãoComercial 4.0 Internacional (CC BY-NC 4.0) 